\title{
Mechanical and physicochemical characterization along with biological interactions of a new Ti25Nb21Hf alloy for bone tissue engineering
}

C. Herranz-Diez, F. J. Gil, J. Guillem-Marti, J.M. Manero(*)

${ }^{a}$ Biomaterials, Biomechanics and Tissue Engineering Group, Department of Materials Science and Metallurgy, Technical University of Catalonia (UPC), ETSEIB, Av. Diagonal 647, 08028 Barcelona, Spain

${ }^{\mathrm{b}}$ Biomedical Research Networking Centre in Bioengineering, Biomaterials and Nanomedicine (CIBERBBN), Campus Río Ebro, Edificio I+D Bloque 5, 1a planta, C/ Poeta Mariano Esquillor s/n, 50018 Zaragoza, Spain

${ }^{\mathrm{C}}$ Centre for Research in NanoEngineering (CRNE) - UPC, C/Pascual i Vila 15, 08028 Barcelona, Spain

*Corresponding author:

Dr. J.M. Manero:

Biomaterials, Biomechanics and Tissue Engineering Group, Department of Materials Science and Metallurgy, Technical University of Catalonia (UPC), ETSEIB, Av. Diagonal 647, 08028 Barcelona, Spain.

E-mail address: jose.maria.manero@upc.edu 


\begin{abstract}
Nowadays, one of the main challenges in metal implants for bone substitution is the achievement of an elastic modulus close to that of human cortical bone as well as to provide an adequate interaction with the surrounding tissue avoiding in vivo foreign body reaction. From this perspective, a new Tibased alloy has been developed with $\mathrm{Nb}$ and $\mathrm{Hf}$ as alloying elements which are known as non-toxic and with good corrosion properties. The microstructure, mechanical behaviour and the physicochemical properties of this novel titanium alloy have been studied. Relationship of surface chemistry and surface electric charge with protein adsorption and cell adhesion have been evaluated due to its role for understanding the mechanism of biological interactions with tissues. The $\mathrm{Ti} 25 \mathrm{Nb} 21 \mathrm{Hf}$ alloy presented a lower elastic modulus than commercial alloys with a superior ultimate strength and yield strength than CP-Ti and very close to Ti6Al4V. It also exhibited good corrosion resistance. Furthermore, the results revealed that it had no cytotoxic effect on rat mesenchymal stem cells and allowed protein adsorption and cell adhesion. The experimental results make this alloy a promising material for bone substitution or for biomedical devices.
\end{abstract}

\title{
Keywords:
}

Titanium based alloy, cell adhesion, protein adsorption, electrochemical behavior, contact angle, in vitro cell culture 


\section{Introduction}

Metallic materials are used in a variety of biomedical devices and are remarkably important for bone substitution to improve the quality of life (QOL) of the patient ${ }^{1}$. The materials currently used for surgical implants include 316L stainless steel (316LSS), cobalt chromium (Co-Cr) alloys and titanium (Ti) and its alloys. However, chemical elements such as $\mathrm{Ni}, \mathrm{Cr}$ and $\mathrm{Al}$ are found to be released from these alloys due to corrosion ${ }^{2}$. A protective oxide layer is typically generated on these alloys acting as a barrier against chemical attack and corrosion, although this oxide layer can be depleted by wear, corrosion or fatigue. These processes produce the release of ions or wear debris which may cause some allergic reaction and biocompatibility problems ${ }^{3-5}$. For instance, the low wear resistance of Ti6Al4V alloy has been demonstrated to induce the release of aluminium (Al) and vanadium $(\mathrm{V})$ ions which are potentially hazardous for human body ${ }^{6}$. Therefore, these elements are now avoided as much as possible as an additive in metallic biomaterials.

Moreover, another main goal in implantology is to replace bone, or tooth, with materials that exhibit a low elastic modulus near to that of human bone without having undesirable reactions. The elastic modulus of bone is $14-20 \mathrm{GPa}^{7}$ while most of the materials used are in the range of $110-240 \mathrm{GPa}^{8}$. This mismatch of the elastic modulus produces stress shielding that eventually leads to implant failure. Bone requires a mechanical stimulus for remodeling; hence, in a bone-implant coupling, it is essential to use materials with rigidity properties similar to bone for improving the load-transfer and favoring bone healing and remodeling ${ }^{9,10}$.

Among metallic biomaterials, $\mathrm{Ti}$ is still the most commonly used biomaterial in implantology due to its high strength, high corrosion resistance, low elastic modulus, chemical stability and biocompatibility ${ }^{11}$. However, a considerable number of bone replacements end with implant failure mainly due to the poor wear resistance and the high elastic modulus of Ti $(110 \mathrm{GPa})$, which is still far from the above mentioned for bone. Thus the development of Ti alloys with excellent combination of high strength and low elastic modulus similar to bone values to replace traditional medical metallic alloys are required. 
Due to the lower elastic modulus exhibited by the $\beta$ (BCC) phase of Ti and its good workability compared with the values presented by the $\alpha(\mathrm{HCP})$ phase $^{12,13}, \beta$ Ti alloys are a relevant field of investigation $^{14-16}$. However, the $\beta$ phase in Ti is only achieved at high temperature. Then, in order to stabilize this phase at low temperature and to reduce the elastic modulus of $\mathrm{Ti}$, nontoxic and nonallergic $\beta$-stabilizing alloying elements such as $\mathrm{Ta}, \mathrm{Nb}, \mathrm{Mo}, \mathrm{Hf}$, and, in some cases $\mathrm{Zr}$ as a neutral element, are used. Several efforts have been concentrated on the production of natively biocompatible alloys; e.g. the $\mathrm{Ti}-\mathrm{Nb}$ and the related $\mathrm{Ti}-\mathrm{Nb}-\mathrm{X}$ system (where $\mathrm{X}=\mathrm{Zr}, \mathrm{Ta}, \mathrm{Au}, \mathrm{O}$ ) have yielded alloys with superelastic strains as high as $4.2 \%$, sufficient for most applications ${ }^{17-19}$ without affecting biocompatibility. Noteworthy, the TiNbHf ternary system presents very interesting properties. Previous studies in our research group ${ }^{20,21}$ showed a decrease in the apparent elastic modulus up to 42 GPa for Ti-16.2Hf-24.8Nb alloy by increasing the cold work percentage. Moreover, in vitro citotoxicity tests, hemolysis tests and platelet tests showed low citotoxicity and excellent hemocompatibility for TiNbHf systems ${ }^{22}$.

Some authors have used a method based on molecular orbital theory introduced by Morinaga et al. for designing low elastic modulus alloys ${ }^{23}$. The resulting properties predictive map was based on two parameters: the average of the bond orders between the alloying elements and the original element (Bo) and the mean energy of the lowest virtual d-orbitals (Md). In the previous study by our research group, this prediction map has been improved by using more precise parameters to design low elastic modulus alloys ${ }^{14}$. In one hand, the bond orders were improved calculating from a natural population analysis $(\mathrm{BO})^{24}$. On the other hand, the energy of occupied orbitals centred in the alloying element (OE) was used instead of the energy of virtual $d$-orbitals. From the resulting map, a Ti alloy presenting 25 wt.\% niobium (Nb) and 21 wt.\% hafnium (Hf) was selected for the present study.

In addition to mechanical properties, superficial implant properties are also very important for tissue integration. Among these properties, wettability and superficial charge are related to the material chemical composition and mediate the tissue-implant interaction through protein adsorption. Wettability, generally referred as hydrophobicity/hydrophilicity, is defined as the capacity of a surface to attract or repulse liquid. Although wettability affects protein adsorption, observations regarding this effect have not always been consistent ${ }^{25}$. The electric charge of a material surface, measured as zeta- 
potential, indicates which entities would be attracted. Negative values of zeta-potential indicate negative surface charge which would attract cations and positively charged proteins while positive values indicate a positively charged surface that would attract negatively charged particles.

The present work aims to study the mechanical, physicochemical and biological properties of a new Ti alloy, Ti25Nb21Hf, designed from the predictive map previously developed in our research group. To achieve this objective, the mechanical and superficial properties of the new Ti alloy were analyzed and compared to those of two commonly used implant biomaterials, Ti and Ti6Al4V. In addition, the protein adsorption and cellular adhesion were also evaluated in vitro.

\section{Materials and methods}

\subsection{Alloy design and sample preparation}

A titanium-25 wt.\% niobium- 21 wt. $\%$ hafnium alloy was produced based on optimization of molecular orbital calculations of electronic structures ${ }^{14}$ towards low modulus of elasticity and the potential for superelasticity. From this predictive map, the selected alloy has an average valence electron number (e/a) of 4.176. This value is near to the one reported by Hao et al. ${ }^{26}$, who recommended it in order to obtain a low elastic modulus. Moreover, the alloy presents a bond order (BO) of $0.61212 \mathrm{eV}$ and an orbital free energy (OE) of $0.15260 \mathrm{eV}$ which are similar to those obtained by M. Gonzalez et $\mathrm{al}^{20,21}$.

The new alloy was fabricated at Fort Wayne Metals Research Corporation (Fort Wayne, Indiana, USA). Bars of diameter $10 \mathrm{~mm}$ and longitude $300 \mathrm{~mm}$ were obtained by means of vacuum arc melting (VAM) and drop casting. The bar was vacuum-homogenized and annealed at $650{ }^{\circ} \mathrm{C}$. Commercially pure grade 2 titanium (CP-Ti) and Ti6Al4V bars were purchased from Outokumpu (Finland) fulfilling the ASTM F 67 standard. Discs of $2 \mathrm{~mm}$ in thickness were cut from CP-Ti, Ti6Al4V and Ti25Nb21Hf. They were polished using 600 and 1,200 grit silicon carbide (SiC) abrasive papers and finally, they were further polished with napped polishing pads with a colloidal silica polishing abrasive (1 and $0.05 \mu \mathrm{m})$. 


\subsection{Microstructure analyses}

Crystallographic studies were carried out by X-ray diffraction (XRD) technique (Difractometer D8 Advance, Bruker ,Billerica, MA, USA ) operated at $40 \mathrm{Kv}, 30 \mathrm{~mA}$ and $\mathrm{CuK}_{\alpha}(\lambda=1,542 \AA)$ radiation. TEM samples were prepared by the jet-polishing method using Tenupol-3 equipment (Struers, Denmark) in a solution of $350 \mathrm{~mL}$ 2-butoxiethanol, $60 \mathrm{~mL}$ perchloric acid and $350 \mathrm{~mL}$ methanol at $10^{\circ} \mathrm{C}$ and $40 \mathrm{~V}$. Thin foils were analyzed by TEM using a JEM 1200 EXII (JEOL, Tokyo, Japan).

\subsection{Mechanical tests}

Tensile specimens of CP-Ti, Ti6Al4V and Ti25Nb21Hf were machined according to ASTM E8M-04. Tensile tests were performed using an Instron 8500 testing machine (Instron, Norwood, MA, USA) at $1.5 \times 10^{-4} \mathrm{~s}^{-1}$ strain rate. All mechanical tests were repeated six times. The main mechanical properties were determined: ultimate tensile strength $\left(\sigma_{\max }\right)$, yield strength $\left(\sigma_{\mathrm{y}}\right)$ and the elastic modulus $(\mathrm{E})$.

\subsection{Corrosion studies}

Electrochemical measurements were performed using a PARSTAT 2273 potentiostat (Princeton Applied Research, Princeton, NJ, USA) in a standard three electrode-setup containing a saturated calomel electrode (SCE) as the reference electrode, a graphite electrode as cathode and specimen $\left(0.78 \mathrm{~cm}^{2}\right.$ for $\mathrm{CP}-\mathrm{Ti}$ and $\mathrm{Ti} 25 \mathrm{Nb} 21 \mathrm{Hf}$ and $1.32 \mathrm{~cm}^{2}$ for Ti6Al4V exposed area) as working electrode. Experiments were performed in Hank's Balanced Salt Solution (HBSS; Sigma-Aldrich) at $37^{\circ} \mathrm{C}$. Specimens were embedded in resin, ultrasonically cleaned in ethanol for $15 \mathrm{~min}$ and immersed into the electrolyte solution. Upon immersion of the specimens into the electrolyte, the open-circuit potential $\left(\mathrm{E}_{\mathrm{oc}}\right)$ was measured for two hours and the data was recorded each second. Subsequently, potentiodynamic electrochemical measurements were carried out incrementing the voltage from -0.3 to $4 \mathrm{~V}$ at a scan rate of $1 \mathrm{mV} / \mathrm{s}$. After that, the voltage was reversed back to the starting value. Assays were monitored by PowerSuite ${ }^{\circledR}$ Electrochemical software. Tafel extrapolation was used to estimate the $\mathrm{E}_{\text {corr }}$ and $\mathrm{I}_{\text {corr }}$ values. Open circuit potential and cyclic voltammetry were conducted according to the ISO 10993-15:2009.

\subsection{Wettability and surface free energy (SFE)}


Contact angles were measured using the sessile drop method with an Oca 15+ plus (Dataphysics, Germany) and analyzed with the SCA20 software (Dataphysics). Total SFE and dispersive and polar components of SFE were determined obtaining contact angles with two different liquids on each substrate surface: ultrapure distilled water (MilliQ), which is a polar liquid, and di-iodomethane, which is a non-polar liquid. A series of at least three drops $(3 \mu \mathrm{l} / \mathrm{drop})$ were used in triplicate at room temperature in a saturated environmental chamber. The surface energy was calculated from contact angles $(\theta)$ according to the Owens and Went approach ${ }^{27}$ :

$\gamma_{1}(1+\cos \theta)=2 \sqrt{\gamma_{s}^{d} \gamma_{l}^{d}}-2 \sqrt{\gamma_{s}^{p} \gamma_{l}^{p}} \quad$ (equation 1)

where $\gamma^{\mathrm{d}}$ and $\gamma^{\mathrm{p}}$ are the dispersive and polar components of SFE, respectively, for solid (s) and liquid (1).

\subsection{Z-potential}

The Z-potential was measured using a SurPASS Electrokineic Analyzer (Anton Paar ; Graz, Austria). A $1 \mathrm{mM} \mathrm{KCl}$ solution was used as electrolyte. The electrolyte solution was adjusted to a starting $\mathrm{pH}=$ 8.0 and automatic titration was performed down to $\mathrm{pH}=2.0$ adding $\mathrm{HCl}$. The apparent $\mathrm{Z}$-potential was calculated using the Fairbrother-Mastin equation ${ }^{28}$.

$\zeta=\frac{d U}{d p} \cdot \frac{\eta}{\varepsilon \cdot \varepsilon_{0}}$

where $\mathrm{dU} / \mathrm{dp}$ is the slope of streaming potential versus pressure, $\eta$ the electrolyte viscosity, $\varepsilon$ the relative liquid permittivity, $\varepsilon_{0}$ the vacuum permittivity and $\kappa$ the specific conductivity of the bulk electrolyte solution

\subsection{Protein adsorption}

Human plasma fibronectin (Sigma-Aldrich, purity $>95 \%$ ) was used as model protein in this study. Fibronectin was diluted in phosphate buffered saline (PBS) at $50 \mu \mathrm{g} / \mathrm{ml}$ and $150 \mu \mathrm{l}$ were added on each sample. Incubation was performed for $2 \mathrm{~h}$ at room temperature. Afterwards, non-adherent protein concentrations were determined using the Micro $\mathrm{BCA}^{\mathrm{TM}}$ Protein Assay Kit (Thermo Scientific, Illinois, USA) according to manufacturer's instructions. Measurements were performed using an ELx800 universal microplate reader (Bio-Tek Instruments, Inc, Winooski, VT, USA) at $\lambda=$ 
$562 \mathrm{~nm}$. The quantity of adsorbed protein was obtained by subtracting the non-adherent protein from the initial added protein. Measurements were performed in triplicate. Results from each sample were normalized versus their corresponding area.

\subsection{Cell culture}

Rat mesenchymal stem cells (rMSC) were extracted from femurs of young Lewis rats and expanded in Advanced DMEM supplemented with 10\% fetal bovine serum, $20 \mathrm{mM}$ HEPES buffer solution, penicillin/ streptomycin antibiotics (50 U/ml and $50 \mu \mathrm{g} / \mathrm{ml}$, respectively) and $2 \mathrm{mM} \mathrm{L}$-glutamine, all from Invitrogen (Carlsbad, CA,USA). Cells were cultured at $37^{\circ} \mathrm{C}$ in humidified atmosphere with $5 \%$ $\mathrm{CO}_{2}$. Cells from passage 5 were used in all the experiments. For cellular assays, samples were sterilized in 70\% ethanol for $30 \mathrm{~min}$ followed by three rinses in PBS.

\subsection{Cytotoxicity}

The cytotoxic effect was evaluated according to the ISO 10993-5 standard by indirect contact. Samples were incubated for $72 \mathrm{~h}$ in complete medium and supernatants were collected. This extracts were serial diluted in complete medium $(1,1: 1,1: 100$ and 1:1000) and transferred to new microplate wells where 5.000 cells were previously seeded. Cells were incubated for $24 \mathrm{~h}$, washed with PBS and lysed with $100 \mu \mathrm{l}$ of M-PER ${ }^{\circledR}$ (Mammalian Protein Extraction Reagent; Thermo Scientific). Viable cells were quantified using the Cytotoxicity Detection Kit ${ }^{\text {PLUS }}$ LDH (Roche Applied Sciences, Penzberg, Germany) following the manufacturer's instructions. Measurements were performed in triplicate and optical densities at $\lambda=492 \mathrm{~nm}$ were obtained. The percentage of viability was calculated using the following formula:

$$
\text { Viability }(\%)=\frac{\text { experimental value }- \text { negative control }}{\text { positive control }- \text { negative control }} \times 100
$$

Where negative control is the tested medium without cells and positive control is cells with complete medium.

\subsection{Cell adhesion assay}

Cells were seeded on samples at a density of 25.000 cells/well and allowed to adhere for $5 \mathrm{~h}$. Then, culture medium was removed; cells were washed in PBS and lysed with $300 \mu 1$ of M-PER $\AA$. The 
Cytotoxicity Detection Kit ${ }^{\text {PLUS }}$ LDH was used as above described. To express the results in cell number a calibration curve with decreasing number of cells was prepared. Experiments were performed in triplicate and results from each sample were normalized versus their corresponding area.

\subsection{Statistical analysis}

All data were expressed as mean values \pm standard deviations. Significant differences between groups were analyzed by ANOVA test followed by post-hoc pairwise comparisons using Tukey's test with a significance level set at $\mathrm{p}<0.05$.

\section{Results and discussion}

\subsection{Microstructure}

XRD patterns (figure 1) showed a microstructure mainly formed by $\beta$-phase with body-centered cubic crystallographic structure as well as a minor phase of martensitic $\alpha^{\prime \prime}$ with an orthorhombic structure (S.G. Pcmm). The corresponding lattice parameters were $\mathrm{a}=3.319 \AA$ for the $\beta$ phase; and $\mathrm{a}=4.88720$ $\AA, \mathrm{b}=3.13210 \AA$ and $\mathrm{c}=4.77410 \AA$ for the martensitic $\alpha^{\prime \prime}$ phase.

Table 1 shows the theoretical crystallographic planes and their corresponding intensities according to the Joint Committee on Powder Diffraction Standards. The two most intense peaks corresponding to $\alpha^{\prime \prime}$ martensitic phase (111 and 002) are partially overlapped by the peak 100 of the $\beta$ phase. However, the (200) peak (third with higher intensity for $\alpha^{\prime \prime}$ martensitic phase) can be seen clearly confirming its presence. Since there is a little $\alpha^{\prime \prime}$-phase, the less intense peaks remain masked. Therefore, the second phase detected was identified to be $\alpha^{\prime \prime}$-martensite of C-centered orthorhombic lattice similar to that reported in Ti-Nb binary system. The XRD patterns obtained have a number of similarities with other $\mathrm{Ti}^{-\mathrm{Nb}^{29,30}}$, Ti-Nb-Ta ${ }^{31}$ or Ti-Nb-Hf ${ }^{32}$ alloys studied in the literature.

TEM images also demonstrated that the alloy was mainly composed of $\beta$-phase equiaxial grains with high dislocation density (Fig. 2). In addition, $\alpha$ '-martensite was observed inside the $\beta$-phase grains. It is well known that the presence of $\omega$-phase precipitates in $\beta$ matrix could be confirmed by electron diffraction pattern ${ }^{33}$. In this case an $\omega$-phase was not observed.

\subsection{Mechanical properties}


The stress-strain results for all the studied materials are shown in Table 2 . Both tensile strength $\left(\sigma_{\max }\right)$ and yield strength $\left(\sigma_{\mathrm{y}}\right)$ are higher than those of CP-Ti and are very close to the values obtained for Ti6Al4V. Similar results were previously found in a study on the mechanical properties of Ti-Nb alloys with different contents of $\mathrm{Nb}^{29}$. In that study, authors found that the elastic modulus decreased and the tensile strength increased while increasing the proportion of $\mathrm{Nb}$ until the formation of an $\omega$ phase, at $26 \%$ of $\mathrm{Nb}$.

It is well known that the presence of $\beta$-phase in a titanium alloy is associated with a reduction in the elastic modulus. In fact, the alloy fabricated in the present study mainly composed of $\beta$-phase grains exhibited a lower elastic modulus compared with CP-Ti or Ti6Al4V alloy. The obtained elastic modulus $(85 \mathrm{GPa})$ is very close to previous values of TiNbHf ternary alloys studied in our research group $^{20,21}$, confirming that addition of $\mathrm{Nb}$ and $\mathrm{Hf}$ decreases the elastic modulus of CP-Ti. Furthermore, these TiNbHf ternary alloys can exhibit very interesting properties since by means of severe plastic deformation (SPD) the mechanical properties could be strongly enhanced ${ }^{20,21}$.

\section{3. Corrosion behaviour}

Materials in contact with body fluids get oxidized releasing ions to the surrounding tissue and the body stream which can be hazardous ${ }^{34}$. A material with high corrosion resistance would minimize this effect and thus, improve biocompatibility. The corrosion resistance of the Ti25Nb21Hf was evaluated using two different methods.

\subsubsection{Open circuit potential}

Fig. 3 shows the open circuit potentials of Ti, Ti6Al4V and Ti25Nb21Hf obtained in HBSS at $37^{\circ} \mathrm{C}$. All three materials showed a clear active to passive oxidation transition at $\mathrm{E}_{\mathrm{oc}}$ near to $0 \mathrm{~V}$, which evidence the formation of a passive protective oxide layer on the surface of all the samples. Noteworthy, the value of $\mathrm{E}_{\mathrm{oc}}$ for the Ti25NbHf alloy is considerably higher than the $\mathrm{E}_{\mathrm{oc}}$ value of the Ti6Al4V alloy and similar to CP-Ti (Table 3). Higher values of $E_{o c}$ are indicative of higher resistance to corrosion under the assay conditions.

The Ti25Nb21Hf and Ti open circuit potential trends were similar. Both materials exhibited an open circuit potential stabilization that was not seen for the Ti6Al4V behaviour. Similar results were found in other studies that used niobium and/or hafnium as Ti alloying elements, suggesting that these 
elements did not change the excellent corrosion behaviour of $\mathrm{Ti}^{34-36}$. Interestingly, $\mathrm{Ti} 25 \mathrm{Nb} 21 \mathrm{Hf}$ presented a higher initial positive slope, stabilizing earlier. This faster oxide layer generation is encouraging for implant purposes ${ }^{38}$.

\subsubsection{Cyclic Voltammetry}

The cyclic voltammetry curves obtained for each material are shown in Fig. 4. The calculated corrosion potential $\left(\mathrm{E}_{\text {corr }}\right)$ for CP-Ti was $\mathrm{E}_{\text {corr }}=-59 \mathrm{mV}$, for Ti6Al4V was $\mathrm{E}_{\text {corr }}=-39 \mathrm{mV}$, whereas for Ti25Nb21Hf alloy was $\mathrm{E}_{\text {corr }} \approx-124 \mathrm{mV}$. The corrosion current density $\left(\mathrm{I}_{\mathrm{cc}}\right)$ values for CP-Ti and Ti6A14V alloy were similar, whilst the value for Ti25Nb21Hf alloy was lower. All three materials reached their respective stable passive current densities as the potential increased, indicating the existence of a passive layer. No breakdown was observed in either of the materials under study.

Although the $\mathrm{E}_{\text {corr }}$ value for Ti25Nb21Hf alloy was lower than CP-Ti and Ti6A14V, the $\mathrm{I}_{\mathrm{cc}}$ value indicates a good passivation with density value lower than CP-Ti and Ti6Al4V, suggesting that the designed alloy possesses an excellent corrosion resistance. This excellent corrosion behaviour is attributed to the oxide layer formed on the surface due to the presence of, in addition to $\mathrm{Ti}, \mathrm{Nb}$ and $\mathrm{Hf}$. High quantities of $\mathrm{Nb}$ repassivate more quickly and the passive film is more stable than low $\mathrm{Nb}$ containing alloys mainly due to the formation of $\mathrm{Nb}_{2} \mathrm{O}_{5}$ phase ${ }^{39-40}$. Hf has also excellent corrosion behaviour, mainly due to the formation of $\mathrm{HfO}_{2}$, which generates a stable surface oxide layer similar to $\mathrm{Ti}^{41}$.

\subsection{Contact angle measurements and SFE calculation}

Fig. 5a shows the contact angles obtained by the sessile drop method on the different materials. The addition of $\mathrm{Nb}$ and $\mathrm{Hf}$ decreased the water contact angle of $\mathrm{CP}-\mathrm{Ti}\left(85^{\circ}\right)$ in the obtained $\mathrm{Ti} 25 \mathrm{Nb} 21 \mathrm{Hf}$ alloy $\left(56^{\circ}\right)$. However, this value was higher compared to the Ti6Al4V value $\left(45^{\circ}\right)$. In contrast, the diiodomethane contact angles were similar for $\mathrm{CP}-\mathrm{Ti}$ and $\mathrm{Ti} 25 \mathrm{Nb} 21 \mathrm{Hf}$ alloy, whereas the values observed in Ti6Al4V alloy were lower. The decrease in the ternary alloy contact angles should be attributed to the hydrophilicity properties of $\mathrm{Nb}^{42}$ and probably $\mathrm{Hf}$.

The lower contact angle values obtained for the studied alloy corresponded to a higher SFE compared to CP-Ti, but similar to the Ti6Al4V alloy (Fig. 5b). Although mainly interactions are attributed to 
dispersive SFE component, no differences were observed between each surface. Then, differences in the alloy SFE are explained by the higher polar SFE component value compared to Ti value.

\subsection{Zeta potential results}

Zeta-potential measurements have shown different electrokinetic behaviour in the interactions at the interface between aqueous electrolyte and each material surface studied. Fig. 6a shows zeta-potential values versus $\mathrm{pH}$ change for a standard $1 \mathrm{mM} \mathrm{KCl}$ solution for Ti, Ti6Al4V and Ti25Nb21Hf. The zeta-potential of both alloys gradually decreased while $\mathrm{pH}$ increased, whereas zeta-potential of $\mathrm{Ti}$ dramatically decreased in the $3-5 \mathrm{pH}$ range. The isoelectric point (IEP) is the $\mathrm{pH}$ at which a surface presents no net electrical charge. Ti exhibited the highest IEP value (3.2) whereas Ti6Al4V and Ti25Nb21Hf alloys presented similar IEP values (2.4 and 2.1 respectively).

The zeta-potentials for each material at $\mathrm{pH} 7$ are shown in Fig. 6b. The less negative zeta-potential value was observed for the Ti25Nb21Hf alloy. Proteins have a specific electric charge at physiological conditions that depends on their amino acid sequence. In this study, Ti and the studied Ti alloys displayed slightly different surface charge properties. Their influences on protein adsorption could display different behaviour, which will be discussed in the protein adsorption section.

\subsection{Cytotoxicity assessment}

Fig. 7 shows the percentage of cell viability after $24 \mathrm{~h}$ of culture in different dilutions of medium extracts from each type of sample. The percentage of viable cells in all conditions was above $90 \%$ with no statistical significant differences between each condition. Similar results were found in a previous study using other $\mathrm{Ti}-\mathrm{Nb}$ and $\mathrm{Ti}-\mathrm{Nb}-\mathrm{Hf}$ alloys compositions ${ }^{43}$. The exposure of cells to different extract concentrations of the new Ti25Nb21Hf alloy demonstrated no cytotoxic effect.

\subsection{Protein adsorption}

Fig. 8 shows the adsorbed amount of fibronectin on each material. The quantity of fibronectin adsorbed on the Ti25Nb21Hf alloy $\left(0.81 \mu \mathrm{g} / \mathrm{cm}^{2}\right)$ was no statistically significant different compared to the adsorbed amount on CP-Ti $\left(0.86 \mu \mathrm{g} / \mathrm{cm}^{2}\right)$ and Ti6Al4V alloy $\left(0.75 \mu \mathrm{g} / \mathrm{cm}^{2}\right)$. The adsorption of proteins on the surface of a metal mainly depends on the physicochemical characteristics of both interactants. Without considering the effect of roughness, since surfaces where polished in the present study, amphoteric and hydrophilic/hydrophobic characteristics become the most influencing surface 
parameters for protein adsorption ${ }^{44}$. The oxidation of metal surfaces generates hydroxyl groups that yield amphoteric characteristics, changing its surface zeta potential as a result of the change in $\mathrm{pH}$. At physiological $\mathrm{pH}$, all the tested surfaces presented anionic character suggesting that should attract cations or positively charged proteins. Fibronectin is a protein with negative net charge that should be repulsed by anionic surfaces. However, in our study fibronectin was well adsorbed on all the studied surfaces, without any statistically significant difference. The hydrophilic/hydrophobic character also plays an important role on protein adsorption. Although there is considerable diversity of opinion regarding protein-adsorption properties of hydrophilic or hydrophobic surfaces ${ }^{45}$, it seems that proteins tend to adsorb stronger to non-polar than to polar surfaces ${ }^{46}$. In fact, no statistical significant differences were found in the levels of adsorbed fibronectin on the different studied surfaces, which presented different SFE values but similar non-polar levels. This could be because the increase in the SFE of Ti25Nb21Hf was not enough for enhancing the protein adsorbed on CP-Ti. In addition, it was found that fibronectin is able to bind to both hydrophilic and hydrophobic surfaces ${ }^{44}$. Then, our results demonstrated that Ti25Nb21Hf alloy is capable to adsorb protein at similar levels than CP-Ti and Ti6Al4V.

\subsection{Cell adhesion}

Cell adhesion is mediated by interaction with preadsorbed proteins during implant integration. Immediately after implantation, proteins from blood are adsorbed onto the implant surface and favour cell adhesion. In order to mimic this process, the cell adhesion assay was performed in medium containing FBS, since proteins in the serum were rapidly adsorbed onto the material surface before cells adhere. Cell adhesion on the CP-Ti, Ti6A14V alloy and Ti25Nb21Hf alloy was quantified 4h after cell seeding (Fig. 9). The number of cells adhered on the different materials showed no statistical significant differences. Although albumin is the most abundant serum protein, it is suspected that after adsorption onto moderately hydrophilic surfaces it is displaced by cell adhesive proteins ${ }^{47}$. One of the main cell adhesive proteins is fibronectin, which was tested in our study without any differences in adsorption levels between the tested surfaces. This finding correlated well with cell adhesion assay, having same amounts of cells on each sample surface. Then, it can be concluded that in vitro 
biological response of the developed titanium alloy was similar to the commonly used $\mathrm{Ti}$ and Ti6Al4V materials.

\section{Conclusions}

In this work, the mechanical, physicochemical and biological properties of a new titanium alloy containing niobium and hafnium were investigated. The addition of 25 wt.\% $\mathrm{Nb}$ and 21 wt.\% $\mathrm{Hf}$ to CP-Ti resulted in a ternary alloy mainly composed of $\beta$-phase grains with $\alpha^{\prime \prime}$-phase martensitic plates. Interestingly, the alloy exhibited excellent mechanical properties, considerably decreasing the elastic modulus of the currently used materials for implantation, CP-Ti and Ti6Al4V alloy, and presenting similar tensile strength values than Ti6Al4V. Moreover, this new Ti alloy also exhibited an excellent corrosion resistance, forming a rapid passive oxide layer. In addition, it exhibited a moderately hydrophilic surface and a lower negative surface charge compared to CP-Ti and Ti6Al4V. In vitro cytotoxicity assays demonstrated non effects on mesenchymal stem cells viability. Finally, the Ti25 $\mathrm{Nb} 21 \mathrm{Hf}$ alloy is capable to adsorb fibronectin and to favour cell adhesion at similar values than CP-Ti and Ti6Al4V alloys.

The interesting mechanical and physicochemical properties of the new developed Ti25Nb21Hf alloy combined with the biological response make it a potential candidate for bone replacement. However, additional studies can be further investigated in order to enhance the mechanical properties. Recently it has been reported that severe plastic deformation techniques (equal channel angular pressing, ECAP, accumulative roll bonding, ARB or high pressure torsion, HPT) are a promising method due to its ability to increase the mechanical strength maintaining a low Young's modulus or even lowering it, in these TiNbHf ternary alloys.

\section{Acknowledgements}

The authors would like to thank the Spanish Government for financial support through MAT201230706 project co-funded by the EU through European Regional Development Funds and the FI fellowship of the AGAUR Agency. Authors would also like to thank the staff of Fort Wayne Metals for their help with material fabrication and Marc Fernández for corrosion experiments assistance. 


\section{REFERENCES}

1. M. Niinomi, M. Nakai, J. Hieda. Development of new metallic alloys for biomedical applications. Acta Biomaterialia 8 (2012) 3888-3903.

2. O. Yoshimitsu, G.Emiko. On the Effects of Hot Forging and Hot Rolling on the Microstructural Development and Mechanical Response of a Biocompatible Ti Alloy. . Biomaterials 2005;26:11-21

3. H.H. Huang, H.Y. Chiu, H.T. Lee, H.W. Yang, K.H. Su, and C.C. Hsu, Ion Release from NiTi Orthodontic Wires in Artificial Saliva with Various Acidities, Biomaterials, 2003, 24, p 3585-3592.

4. Lu XY, Bao X, Huang Y, Qu YH, Lu HQ, Lu ZH. Mechanisms of cytotoxicity of nickel ions based on gene expression profiles. Biomaterials 2009, 30, 141-148.

5. K.Cederbrant, C.Anderson, M.Marcusson, P.Hultman. Cytokine Production, Lymphocyte Proliferation and T-Cell Receptor Vß Expression in Primary Peripheral Blood Mononuclear Cell Cultures from Nickel-Allergic Individuals. Int Arch Allergy Immunol, 132; 2003, p.373-379.

6. Urban RM, Jacobs JJ, Tomlinson MJ, Gavrilovic J, Black J, Peoc'h M. Dissemination of wear particles to the liver, spleen, and abdominal lymph nodes of patients with hip or knee replacement. J. Bone Joint Surg Am. 2000 Apr;82(4):457-76.

7. R. Boyer, G. Welsch,E.W. Collings. Materials properties handbook. Titanium Alloys..Ed ASM International. (1994) ISBN: 0-87170-481-1.

8. Geetha M, Singh AK, Asokamani R, Gogia AK. Ti based biomaterials, the ultimate choice for orthopaedic implants - A review. Prog Mater Sci [Internet]. 2009;54(3):397-425.

9. Christopher Boyle, Il Yong Kim. Comparison of different hip prosthesis shapes considering microlevel bone remodeling and stress-shielding criteria using three-dimensional design space topology optimization. Journal of Biomechanics. Volume 44, Issue 9, 3 June 2011, Pages 1722-1728

10. William R. Thompsona, Clinton T. Rubinb, Janet Rubina. Mechanical regulation of signaling pathways in bone. Gene. Volume 503, Issue 2, 25 July 2012, Pages 179-193

11. D.M. Brunette, M. Textor, P. Thomsen. Titanium in Medicine. M. Science, Surface Science, Engineering, Biological Responses and Medical Applications.(2001).ISBN: 978-3-642-631191

12. H.Y. Kim, Y. Ohmatsu, J.I. Kim, H. Hosoda, and S. Miyazaki. Mechanical properties and shape memory behaviour of Ti-Nb alloys. Mater. Trans., 2004, vol. 45, pp. 1090-95.

13. T. Ozaki, H. Matsumoto, S. Watanabe, and S. Hanada. Beta TiNbSn alloys with low young's modulus and high strength. Mater. Trans., 2004, vol. 45, pp. 2776-79.

14. M. Arciniegas, J. Peña, J.M. Manero, J.C. Paniagua, F.J.Gil. Quantum parameters for guiding the design of Ti alloys with shape memory and low elastic modulus. Phil. Mag. Vol. 88.2008, 2529-2548. 15. M. Arciniegas, J.M. Manero, J. Peña, F.J. Gil, J.A. Planell. Study of New Multifunctional Shape Memory and Low Elastic Modulus Ni-Free Ti Alloys. Metall.Trans. A. Vol. 39A, 2008. 743-751. 
16. M. Arciniegas, J. Peña, F.J. Gil, J.M. Manero. In-vitro response of pre-osteoblastic MG63 cells on Ni-free Ti shape memory substrates. Journal of Biomedical Materials Research: Part B - Applied Biomaterials. Volume 101B, Issue 5, July 2013,pages 709-720.

17. Miyazaki S, Kim HY, Hosoda H. Development and characterization of Ni-free Ti-base shape memory and superelastic alloys. Mater Sci Eng, A 2006;438-440:18-24.

18. Hosoda H, Fukui Y, Inamura T, Wakashima K, Miyazaki S, Inoue K. Mechanical properties of Tibased shape memory alloys. Mater Sci Forum 2003;426-432:3121-6.

19. Kim HY, Ikehara Y, Kim JI, Hosoda H, Miyazaki S. Martensitic transformation, shape memory effect and superelasticity of Ti-Nb binary alloys. Acta Mater 2006;54:2419-29.

20. M. González, J. Peña, J.M.Manero, M.Arciniegas, F.J. Gil. Optimization of the Ti-16.2Hf24.8Nb-1Zr Alloy by Cold Working. J.Materials Engineering and Performance. Vol.18 2009. 506-10. 21. M. González, J. Peña, F.J. Gil, J.M. Manero. Low modulus Ti-Nb-Hf alloy for biomedical applications. Materials Science \& Engineering C. Volume 42, 1 September 2014, Pages 691-695.

22. M.Ramalingam, A.Tiwari, H.Kobayashi. Integrated Biomaterials for Biomedical Technology: Chapter 6: New kind of titanium alloys for biomedical applications. John Wiley \& Sons. 2012.

23. M. Morinaga and N. Yukawa, in Computer-Aided Innovation of New Materials (CAMSE '90), M. Doyama et al. eds., Elsevier, North-Holland Inc., New York, p.803.

24. J.E. Carpenter, F. Weinhold. Analysis of the geometry of the hydroxymethyl radical by the "different hybrids for different spins" natural bond orbital procedure. J.Molecular Structure: THEOCHEM, Volume 169, 1988, Pages 41-62.

25. Gittens RA, Scheideler L, Rupp F, Geis-Gerstorfer J, Schwartz Z, Boyan BD. A review on the wettability of dental implant surfaces:Biological and clinical aspects.Acta Biomater. 201410:2907-18. 26. Hao Y.L., Li S.J., Sun S.Y., Zheng C.Y., Yang R. Elastic deformation behaviour of Ti-24Nb4Zr-7.9Sn for biomedical applications. Acta Biomater vol 3 (2008) 277-286.

27. D.K. Owens, R.C. Wendt. Estimation of the surface free energy of polymersJ. Appl. Polym. Sci 1969, 13:1741-1747.

28. K.L. Mittal. Advances in contact angle wettability and adhesión. Vol 1. Scrivener publishing \& Wiley. (2013) ISBN. 978-1-118-47292-7.

29. Hon, Y. H. \& Wang Y.N, J. Y. and P. Composition/Phase Structure and Properties of TitaniumNiobium Alloys. Mater. Trans. 44, 2384 (2003).

30. H.Y. Kim, Y. Ikehara, J.I. Kim, H. Hosoda, S. Miyazaki. Martensitic transformation, shape memory effect and superelasticity of $\mathrm{Ti}-\mathrm{Nb}$ binary changes in mechanical properties of $\mathrm{Ti}$ alloys in relation to alloying additions of Ta and Hf. 14th Int. Conf. Strength Mater. 483-484, 153-156 (2008). [31] Zhou, Y.L., Niinomi, M. Akahori, T. Changes in mechanical properties of Ti alloys in relation to alloying additions of Ta and Hf. 14th Int. Conf. Strength Mater. 483-484, 153-156 (2008). 
32. Hon, Y. H., Wang, J. Y. \& Pan, Y. N. Influence of hafnium content on mechanical behaviors of Ti-40Nb-xHf alloys. Mater. Lett. 58, 3182-3186. (2004).

33. D. De Fontaine and O. Buck. A Monte Carlo simulation of the omega phase transformation. Philos. Mag. Vol 27, 1973 p697.

34. D. M. Brunette, P. Tengvall, M. Textor, P. Thomsen. Titanium in medicine: material science, surface science, engineering, biological responses, and medical applications. ISBN: 978-3-642-63119-

1. (Springer, 2001).

35. Raabe, D., Sander, B., Friák, M., Ma, D. \& Neugebauer, J. Theory-guided bottom-up design of Ltitanium alloys as biomaterials based on first principles calculations: Theory and experiments. Acta Mater. 55, 4475-4487 (2007).

36. Nobuhito, S., Niinomi, M., Toshikazu, A., Takashi, S. \& Tadahiko, F. Effects of Alloying Elements on Elastic Modulus of Ti-Nb-Ta-Zr System Alloy for Biomedical Applications. Mater. Sci. Forum 449-452, 1269-1272 (2004).

37. Zhou, Y.-L., Niinomi, M. \& Akahori, T. Dynamic Young's Modulus and Mechanical Properties of Ti-Hf alloys. Mater. Trans. 45, 1549 (2004).

38. Vasilescu E, Drob P, Raducanu D, Iordachescu D, et al. In vitro biocompatibility and corrosion resistance of a new implant titanium base alloy. J Mater Sci Mater Med. (2010) 1959-68.

39.M. Long, H.J. Rack. Titanium alloys in total joint replacement-a materials science perspective. Biomaterials 19 (1998) 1621-1639

40. Kobayashi, E., Wang, T.J., Doi, H., Yoneyama, T., and Hamanaka, H. Mechanical properties and corrosion resistance of Ti-6Al-7Nb alloy dental castings. J Mater Sci Mater Med. 1998; 9: 567-574

41. Z. Cai, M. Koike, H. Sato, M. Brezner, Q. Guo, O. Okuno, T. Okabe. Electrochemical characterization of cast Ti-Hf binary alloys. Acta Biomaterialia, Vol. 1, Issue 3, 2005, Pages 353-35

42. Wang XJ, Li YC, Lin JG, Yamada Y, Hodgson PD, Wen CE. In vitro bioactivity evaluation of titanium and niobium metals with different surface morphologies. Acta Biomater. 2008; 4(5):1530-5.

43. Wang BL, Li L, Zheng YF. In vitro cytotoxicity and hemocompatibility studies of Ti-Nb, Ti-Nb$\mathrm{Zr}$ and Ti-Nb-Hf biomedical shape memory alloys. Biomed Mater. 2010 Aug;5(4):044102

44. M. Pegueroles, C. Tonda-Turo, J.A. Planell, F.J, Gil, C. Aparicio. Adsorption of Fibronectin, Fibrinogen, and Albumin on TiO2: Time-Resolved Kinetics, Structural Changes, and Competition Study. Biointerphases (2012) 7:48

45. Hung A, Mwenifumbo S, Mager M, Kuna JJ, Yarovsky I, Stevens MM. Ordering surfaces on the nanoscale: implications for protein adsorption. J Am Chem Soc. 2011;133(5):1438-50.

46. Anand G, Sharma S, Dutta AK, Kumar SK, Belfort G. Conformational transitions of adsorbed proteins on surfaces of varying polarity. Langmuir. $2010 \mathrm{Jul}$ 6;26(13):10803-11.

47. Arima, Y; Iwata, H. Effect of wettability and surface functional groups on protein adsorption and cell adhesion using well-defined mixed self-assembled monolayers. Biomaterials 2007, 3074-3082. 


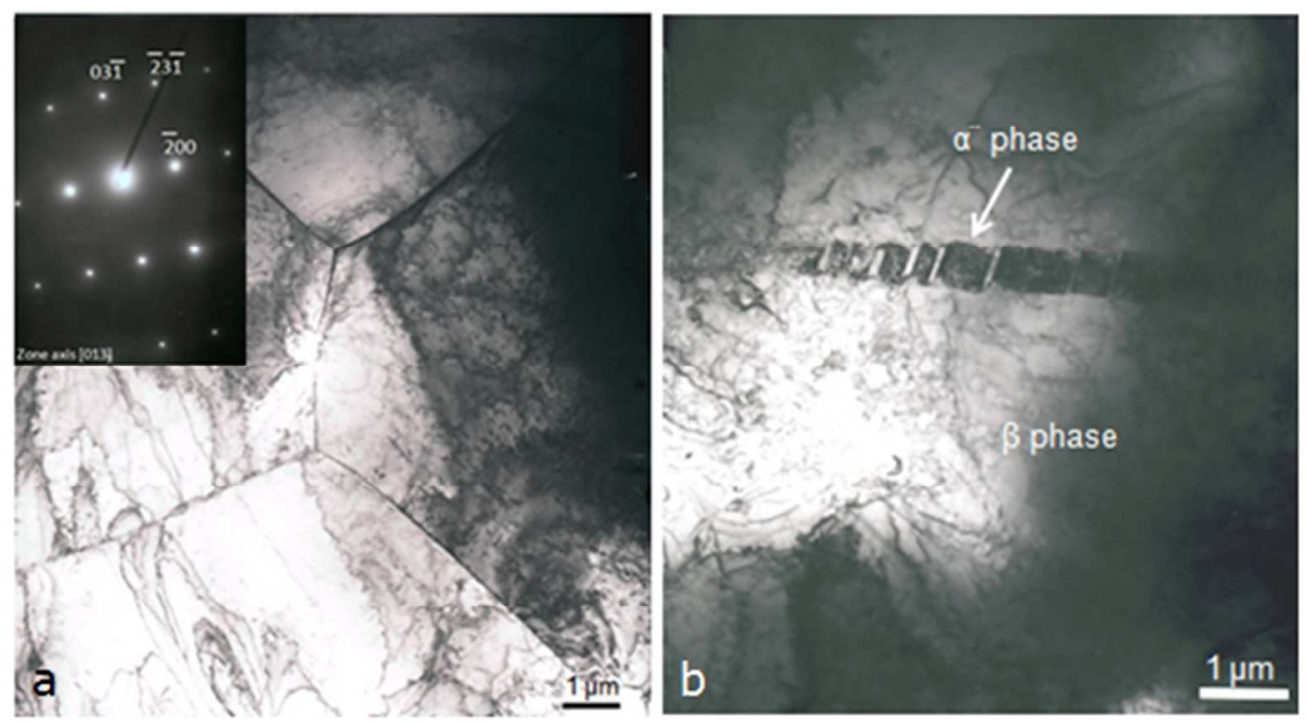

TEM images of the Ti25Nb21Hf alloy. Zone axis [013]. $147 \times 81 \mathrm{~mm}(96 \times 96 \mathrm{DPI})$ 
1

2

3

4

5

6

7

8

9

10

11

12

13

14

15

16

17

18

19

20

21

22

23

24

25

26

27

28

29

30

31

32

33

34

35

36

37

38

39

40

41

42

43

44

45

46

47

48

49

50

51

52

53

54

55

56

57

58

59

60

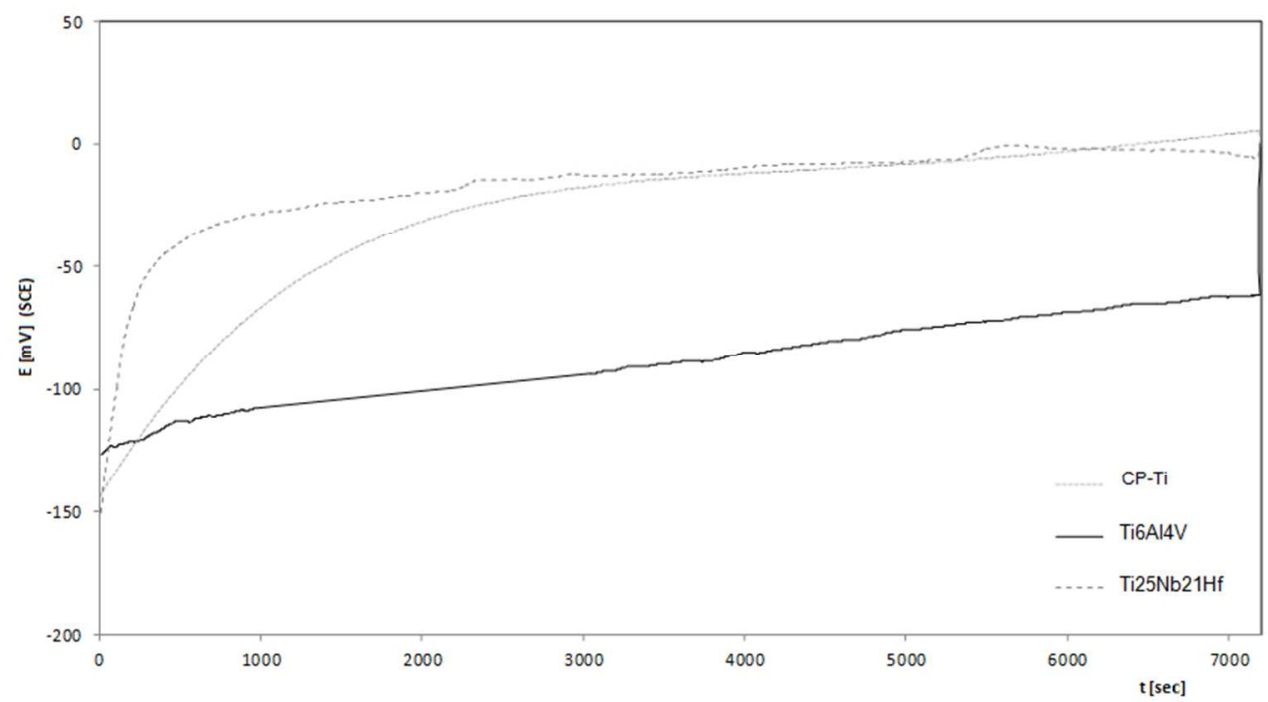

Open-circuit electrode potential as a function of time for the three materials under study in Hank's Balanced Salt Solution at $37^{\circ} \mathrm{C}$ $73 \times 40 \mathrm{~mm}(300 \times 300 \mathrm{DPI})$ 


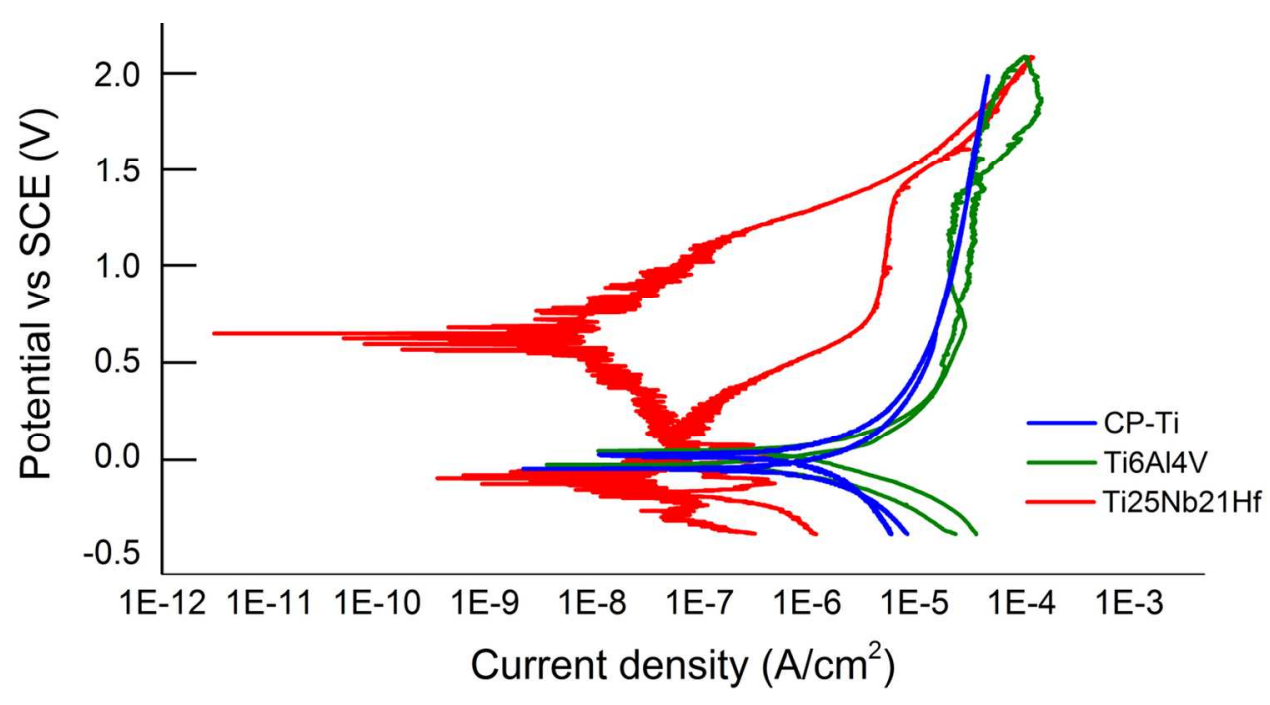

Cyclic voltammetry curves of Ti and Ti6Al4V and Ti25Nb21Hf alloys. $130 \times 68 \mathrm{~mm}(300 \times 300 \mathrm{DPI})$ 
1

2

3

4

5

6

7

8

9

10

11

12

13

14

15

16

17

18

19

20

21

22

23

24

25

26

27

28

29

30

31

32

33

34

35

36

37

38

39

40

41

42

43

44

45

46

47

48

49

50

51

52

53

54

55

56

57

58

59

60
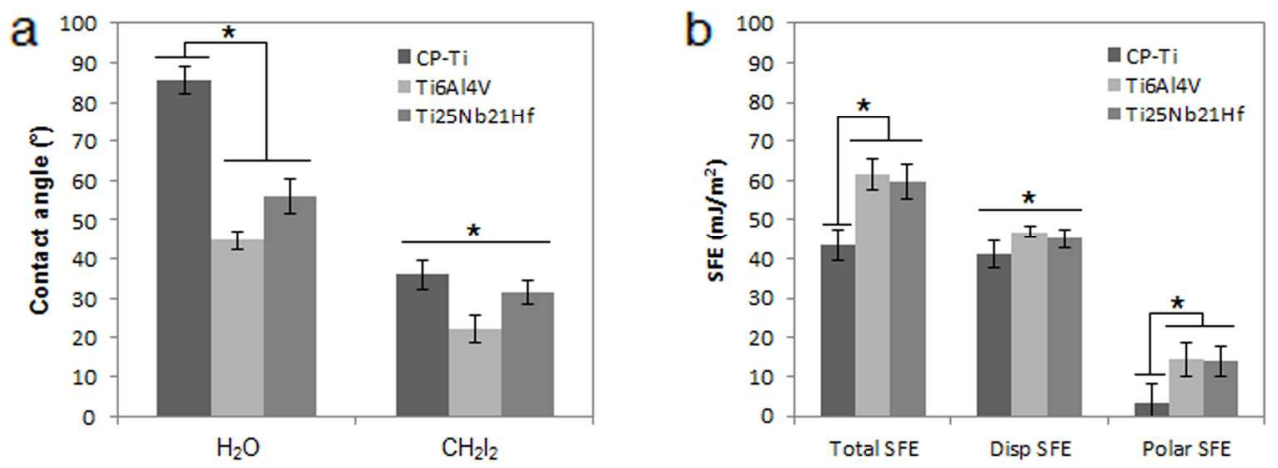

(a) Contact angles for water (H2O) and diiodomethane (CH2I2) and (b) total surface free energy (SFE), dispersive (Disp) and polar components of SFE of Ti and Ti6Al4V and Ti25Nb21Hf alloys. The asterisk means differences between samples with $\mathrm{p}<0.05$. $189 \times 69 \mathrm{~mm}(300 \times 300$ DPI $)$ 

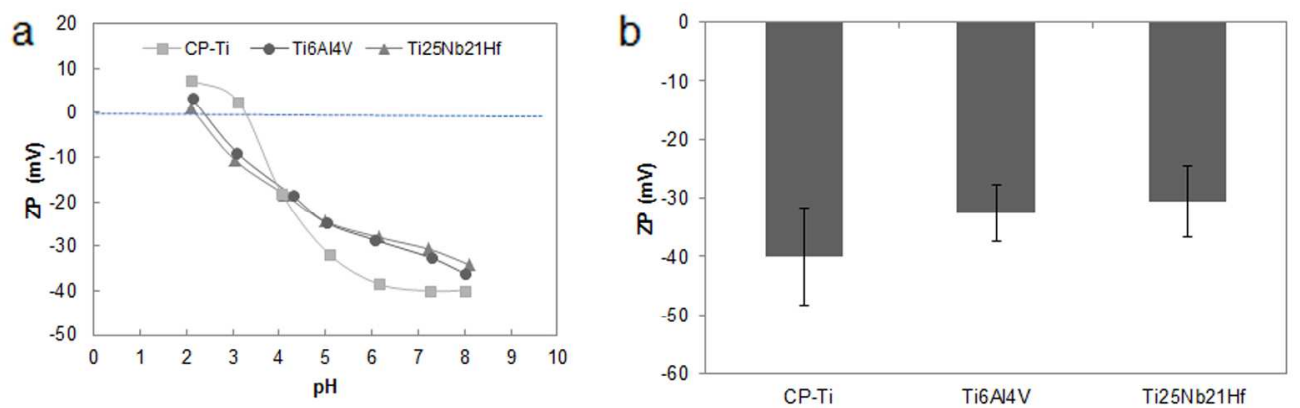

(a) $\mathrm{pH}$ dependence of the zeta-potential for Ti, Ti6Al4V and TiNbHf in a $\mathrm{KCl}$ electrolyte with a concentration $1 \mathrm{mM}$ (a) and (b) Zeta-potentials of the different samples at $\mathrm{pH} 7$ (b). $276 \times 89 \mathrm{~mm}(300 \times 300 \mathrm{DPI})$ 
Cell viability of rMSCs after $24 \mathrm{~h}$ exposure with different extract dilutions. $104 \times 75 \mathrm{~mm}(96 \times 96 \mathrm{DPI})$ 


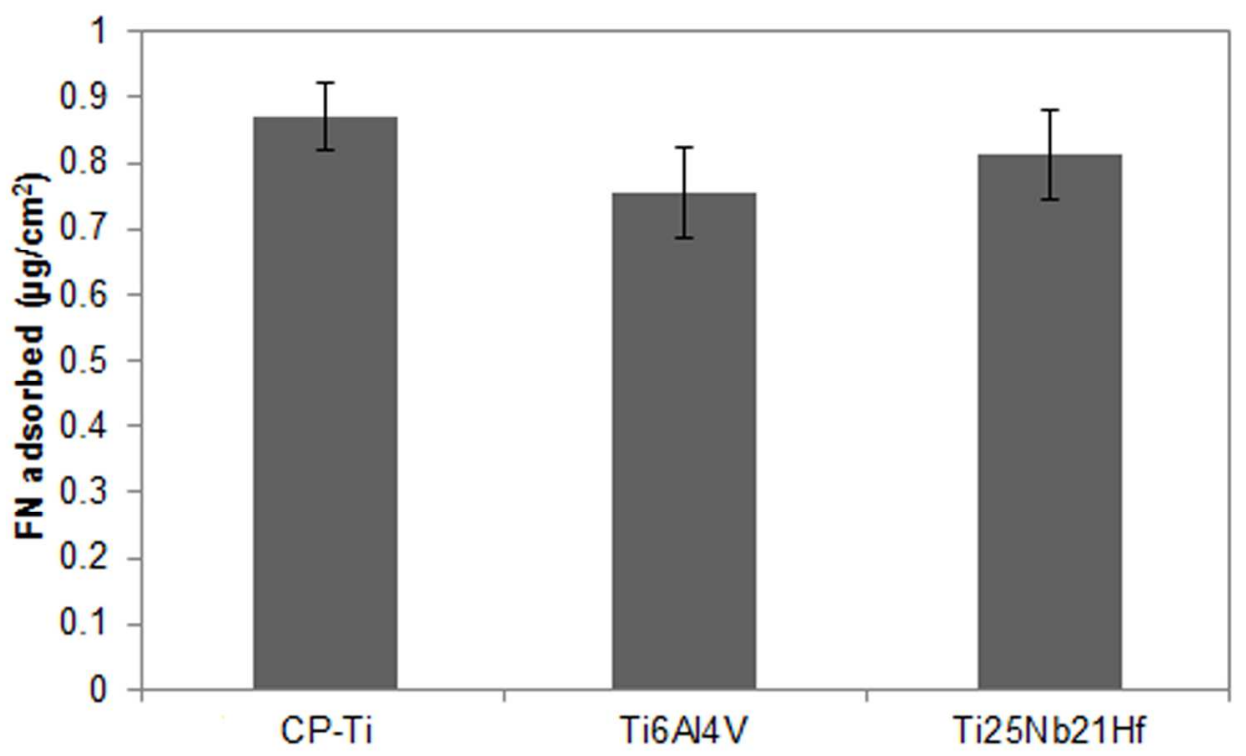

Fibronectin adsorption onto the different tested materials after $2 \mathrm{~h}$ of incubation at room temperature $126 \times 76 \mathrm{~mm}(300 \times 300 \mathrm{DPI})$ 


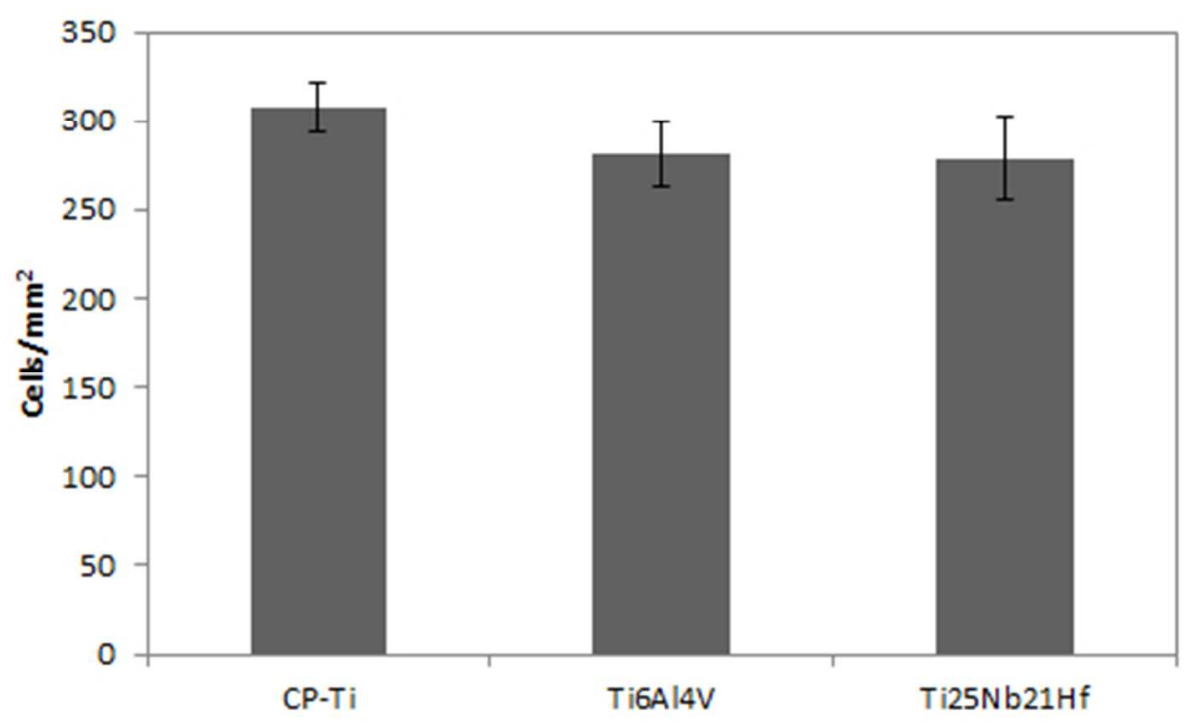

Adhesion of rMSCs (cells $/ \mathrm{mm} 2$ ) onto the three tested materials. $127 \times 76 \mathrm{~mm}(96 \times 96 \mathrm{DPI})$ 


\begin{tabular}{ccccc}
\hline Phase & hkl & $\mathrm{d}(\mathrm{nm})$ & $2 \theta$ & $\mathrm{I}(\%)$ \\
\hline$\alpha^{\prime \prime}$ & 200 & 0.24431 & 36.757 & 24 \\
$\alpha^{\prime \prime}$ & 002 & 0.23869 & 37.655 & 33 \\
$\boldsymbol{\beta}$ & $\mathbf{1 1 0}$ & $\mathbf{0 . 2 3 4 6 6}$ & $\mathbf{3 8 . 3 2 6}$ & $\mathbf{1 0 0}$ \\
$\alpha^{\prime \prime}$ & 111 & 0.23078 & 38.997 & 100 \\
$\alpha^{\prime \prime}$ & 201 & 0.21748 & 41.488 & 14 \\
$\alpha^{\prime \prime}$ & 202 & 0.17073 & 53.639 & 14 \\
$\boldsymbol{\beta}$ & $\mathbf{2 0 0}$ & $\mathbf{0 . 1 6 5 9 6}$ & $\mathbf{5 5 . 3 1}$ & $\mathbf{1 2}$ \\
$\alpha^{\prime \prime}$ & 113 & 0.13624 & 68.86 & 20 \\
$\boldsymbol{\beta}$ & $\mathbf{2 1 1}$ & $\mathbf{0 . 1 3 5 0 7}$ & $\mathbf{6 9 . 5 4 2}$ & $\mathbf{1 7}$ \\
$\boldsymbol{\beta}$ & $\mathbf{2 2 0}$ & $\mathbf{0 . 1 1 7 1 2}$ & $\mathbf{8 2 . 2 5}$ & $\mathbf{4}$ \\
$\boldsymbol{\beta}$ & $\mathbf{3 1 0}$ & $\mathbf{0 . 1 0 4 5 9}$ & $\mathbf{9 4 . 8 6 8}$ & $\mathbf{5}$ \\
\hline
\end{tabular}

http://mc.manuscriptcentral.com/JBA 


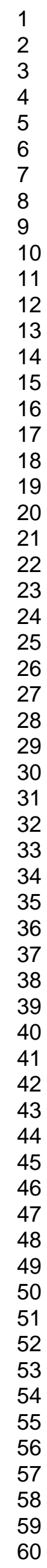

\begin{tabular}{cc}
\hline Material & $E_{\text {open circuit }}[\mathrm{mV}]$ \\
\hline CP-Ti & $2.5 \pm 15$ \\
Ti6Al4V & $-58 \pm 4$ \\
Ti25Nb21Hf & $-6 \pm 15$ \\
\hline
\end{tabular}

http://mc.manuscriptcentral.com/JBA 